\title{
REPAYMENT AND EXCLUSION IN A MICROFINANCE EXPERIMENT
}

\author{
Jean-Marie Baland \\ Email:jean-marie.baland@fundp.ac.be \\ University of Namur \\ BREAD and CEPR \\ Lata Gangadharan \\ Email:Lata.Gangadharan@monash.edu \\ Monash University
}

Pushkar Maitra

Email:Pushkar.Maitra@buseco.monash.edu.au Monash University

Rohini Somanathan

Email:rohini@econdse.org

Department of Economics

Delhi School of Economics

Working Paper No. 227 


\title{
Repayment and Exclusion in a Microfinance Experiment*
}

\author{
Jean-Marie Baland, Lata Gangadharan, Pushkar Maitra and Rohini Somanathan ${ }^{\dagger}$
}

February 5, 2013

\begin{abstract}
Microfinance groups often engage in a variety of collective activities not directly related to credit. Groups can sanction members who default on their loans by excluding them from these activities. Our experiment is designed to explore the effectiveness of such sanctions in improving repayment incentives. Groups of 10 members are provided with joint-liability loans for a specific investment project. If groups repay their loans, contributing members have the option of excluding other members and those that remain play a public goods game. By varying loan sizes across groups and allowing for heterogeneous gains from the public good within groups, we identify the role of incentives in repayment decisions. In line with theoretical predictions, groups with the largest repayment burdens have the highest default rates and within groups, individual decisions to contribute to loan repayment depend on gains from the public good game.
\end{abstract}

JEL Codes: C9, G21, O12.

Key Words: Microfinance, Joint Liability, Social Exclusion, Public Good, Heterogeneous Productivity, Laboratory Experiments.

\footnotetext{
*We have benefitted from comments on earlier versions of the paper from Parikshit Ghosh and Paul Frijters. Funding is provided by AusAID under the Australian Development Research Award (ADRA) Program and is part of the project "Microfinance Beyond Group Lending: An Experimental Approach". Jean-Marie Baland is grateful for the financial support provided by the European Research Council (AdG-230290-SSD). Human Ethics Approval obtained through Monash University (Project Number CF09/1730 - 2009000949).

${ }^{\dagger}$ Baland: University of Namur, BREAD and CEPR, Gangadharan and Maitra: Monash University, Somanathan: Delhi School of Economics.
} 


\section{Introduction}

Many microfinance groups engage in collective activities not explicitly related to credit. For example, the rules of Grameen membership specifically mention the obligation to help others in difficulty as well as to take part in all social activities collectively. ${ }^{1}$ Members of Self-Help groups, the dominant form of microfinance in India, often participate in village governance, school nutrition programs and a range of other productive and social activities. ${ }^{2}$ Ugandan microfinance members often form associations called Munno Mukabi, that organize social functions such as weddings and burials (Sebstad and Cohen, 2001). In Kenya, about one fourth of the Roscas in Kibera also perform additional functions, such as long term investment projects, health insurance or self-employment schemes (Anderson and Baland, 2002).

The multi-faceted functions of these groups provide them with the capacity to sanction members who default on their loans by excluding them from valuable collective activities. Such informal enforcement mechanisms have been shown to be effective in a variety of historical and contemporary contexts where formal institutions are weak (Greif, 1993; Putnam, 1994; Aoki, 2001; Platteau, 2006). In the group lending literature, the theoretical case for higher repayment rates through sanctions is also well-established (Besley and Coate, 1995). This paper provides experimental evidence that explicitly links repayment incentives and default rates to exclusionary practices within groups.

In our laboratory experiment, groups of 10 play a three-stage game. ${ }^{3}$ Each group member borrows to invest in a risky project and, if the project succeeds, decides whether or not to contribute towards loan repayment. If contributions are high enough to repay the group loan, all contributors have the opportunity to exclude other members. Those remaining in the group then play a public good game which generates a positive surplus for each of them. Participation in this stage of the game mirrors the access to benefits from collective activities in the field.

To identify the role of repayment incentives as distinct from altruism or norm-driven behavior that has been emphasized in the experimental literature, we exogenously vary loan sizes across groups and the benefits from the public good within them. Moral hazard in loan repayment decisions is most likely to affect groups with larger loans and individuals within groups who have the least to gain from the public good. In line with our theoretical predictions, we find that members with

\footnotetext{
${ }^{1}$ These are 2 of the 16 decisions that each member must commit to on joining the Bank.

${ }^{2}$ Of over 1,000 groups studied by Baland, Somanathan, and Vandewalle (2008), $80 \%$ are engaged in collective activities that are not related to saving and credit. These include school meal contracts, visits to government officials and helping members resolve family disputes. The groups studied by Rai and Ravi (2011) provide health insurance in addition to credit.

${ }^{3}$ While the early theoretical literature in this area focussed on groups of two members, micro finance groups in the field are typically between 5 and 20 members and we designed our experiment to better reflect these group sizes.
} 
successful projects in groups with small loans almost always contribute to loan repayment whereas only half of those with the largest loans do so. In the latter case, those with high returns from the public good are twice as likely as other members to contribute towards loan repayment in the first stage of the game.

The heterogeneous returns from the public good in our experiment have natural empirical counterparts. Members in groups that engage in collective activities receive differential benefits from them that depend on their income and other characteristics. For example, women with children benefit from school interventions or child-care arrangements, smaller households from the sharing of labor and those with land gain most from infrastructure that improves agricultural productivity. Attrition rates observed in the microfinance sector are hard to interpret because they are the combined result of expulsion and voluntary departures. An advantage of our experimental design is that it uses exogenous variation in the returns from the public good to isolate the effect of social sanctions on repayment behaviour.

Our paper is closely related to two strands of the experimental literature. The first consists of microfinance experiments. These compare loan repayment and monitoring decisions in joint and individual liability contracts. They provide a number of insights into repayment behavior, but groups engage only in credit and investment activities and sanctions are not explicitly incorporated. ${ }^{4}$ A second, more established literature uses public good games to illustrate how sanctions can discipline free riders and increase cooperation in social dilemmas (Ostrom, Walker, and Gardner, 1992; Fehr and Gachter, 2000). In some of these games, sanctions are implemented by voting out uncooperative members (Cinyabuguma, Page, and Putterman, 2005). Experiments which allow for heterogeneity in benefits from the public good find that agents with higher marginal returns are both more willing to sanction uncooperative behavior and to contribute to the public good. ${ }^{5}$ Our results are broadly consistent which these findings and we see our main contribution as linking endogenously determined sanctions to repayment behavior. In doing so, we are able to provide an explanation for the varying rates of group survival and the selective attrition of members from micro finance groups. ${ }^{6}$

\footnotetext{
${ }^{4}$ Giné, Jakiela, Karlan, and Morduch (2010) show that group lending increases risk-taking behavior, Abbink, Irlenbusch, and Renner (2006) observe higher repayment rates under group lending and Cason, Gangadharan, and Maitra (2012) compare outcomes (monitoring and repayment rates) under individual and group lending and find similar performance when the cost of monitoring does not vary.

${ }^{5}$ See Tan (2008); Fellner, Lida, Kroger, and Seki (2010); Reuben and Riedl (2009); Nikiforakis (2008)

${ }^{6}$ See Baland, Somanathan, and Vandewalle (2008) for empirical evidence on patterns of group survival and the non-random attrition of members within Self Help Groups.
} 


\section{A theoretical framework}

Consider a group of $n$ individuals, each of whom would like to borrow the same fixed amount to invest in a self-employment project. The project is risky and the return is $\rho$ with probability $\pi$ and zero otherwise. Loans are given by an external lender to the entire group and members are jointly responsible for repayment. The per member repayment required for a loan of size $l$ is $R_{l}$ so the group owes the lender a total of $n R_{l}$.

Groups have limited liability and lenders have no enforcement capacity. Incentives to repay loans rely on internal sanctions within groups. Sanctions take the form of exclusion from the benefits of collective activities undertaken by the group. The benefits from such activities vary across individuals and also depend on the size and composition of the group undertaking them. This captures empirically important aspects of the types of collective action in which such groups are engaged. For example, large groups may be more effective in risk-pooling schemes and political campaigns, members with sizable land holdings rely on joint harvesting efforts and those eligible for government programs benefit from collective action that improves their implementation.

We model repayment, exclusion and collective action as a three-stage game. Each group contains equal numbers, $N_{a}$ and $N_{b}$, of two types of members $a$ and $b$. In Stage 1 of the game, members of both types receive loans, project returns are realized and successful members make a binary decision of whether or not to contribute towards loan repayment. If there are enough contributors, the group loan is repaid through equal payments by all those who choose to contribute. If not, the group is immediately dissolved and cannot engage in any collective activities. Groups that repay their loans may have some successful members who choose not to contribute towards repayment. We call these defaulting members. In Stage 2 of the game, all contributing members can vote against any one member. A member who receives more than one vote against her is excluded from the collective activity. In Stage 3 the collective activity takes place. This is modeled as a variant of a public good game.

In the public good game, each remaining member has a given endowment, $\omega$, and decides the amount $g_{i}$, to contribute to a group account. Total benefits from this stage are the sum of the residual private endowment and gains from the public good. Public good gains in turn depend on the composition of the group and $a$-types are more productive in the sense that their contribution has a larger multiplier effect on the value of the public good. They also benefit more from a given group fund. These differences between the types are captured by two parameters, $\alpha_{a}$ and $\alpha_{b}$, with $\alpha_{a}>\alpha_{b}$, i.e., the $a$-Types are more productive than the $b$-Types. Specifically, if the total contributions to the group account are given by $C$, and $n_{a}$ and $n_{b}$ are the numbers of each type 
that participate, individual benefits from the public good for $i \in\{a, b\}$ are given by

$$
v_{i}=\alpha_{i} \frac{n_{a} \alpha_{a}+n_{b} \alpha_{b}}{n_{a}+n_{b}} C
$$

We refer to the term $\frac{n_{a} \alpha_{a}+n_{b} \alpha_{b}}{n_{a}+n_{b}}$ as the average quality $(q)$ of the group. The benefit to type $i$ from the third stage of the game is then given by

$$
G_{i}=\left(\omega-g_{i}\right)+\alpha_{i} q C
$$

Since $\alpha_{a}$ is greater than $\alpha_{b}$, if both types make equal contributions to the public account, then $G_{a} \geq G_{b}$. We also make the standard assumption of $\alpha_{a} q<1$, so that unilateral increases in contributions are never privately optimal.

\section{Characterizing Equilibria}

Repayment decisions in the first stage of the game are based on a comparison of the costs of repayment with those of exclusion. A member of type $i$ with a loan of size $l$ will contribute whenever

$$
\frac{n R_{l}}{k}<G_{i}^{e}
$$

where $k$ is the expected number of contributors and $G_{i}^{e}$ is the expected gain from remaining in the game. Such repayment games are characterized by multiple equilibria since the repayment burden for each member decreases in the number of contributors.

Suppose that there are $j$ successful projects within the group. Repayment by all successful members of the group is an equilibrium if even the $b$-Types who gain relatively less from the public good are willing to contribute. This will be the case if

$$
\frac{n R_{l}}{j} \leq G_{b}
$$

Note however that even when this inequality holds, default by all members can also be an equilibrium. No member in this case has an incentive to deviate from this equilibirum as any member 
who decides to contribute must reimburse the entire loan, $n R_{l}$ and is unable to exclude any other member from the group activity. ${ }^{7}$ This deviation is not profitable if $n R_{l}>G_{a}$.

Repayment by some members and default by others may also be an equilibrium. These asymmetric equilibria are of particular interest to us because they provide empirical predictions on how repayment behavior varies by loan size and type. Consider, for example, a group in which there are $j$ members with successful projects of whom $j-1$ are of Type $a$. Both types contribute to repayment if (3) holds. If, on the other hand, this inequality is reversed and $G_{a}>\frac{n R_{l}}{j-1}$, we have a separating equilibrium in which Type $a$ members repay whereas Type $b$ default. Such separating equilibria are most likely for large loans. When loans are small enough, the benefits from Stage 3 exceed required contributions by both types and all successful members benefit from contributing to loan repayment. ${ }^{8}$

Analyzing incentives and behavior in the second and third stages of our game is complicated by the fact that zero contributions is the unique Nash equilibrium in the public good game. This equilibrium implies equal payoffs of $\omega$ for both types in Stage 3. In this case, the exclusion of defaulters in Stage 2 is costless. However, Nash behavior is hardly ever observed in experiments on one-shot public good games and average contributions in the literature typically range from $40 \%$ to $60 \%$ of the optimal level. A variety of explanations have been offered for this behavior such as altruism, myopia or implicit reciprocity. ${ }^{9}$ If these behavioral models are valid, then experimental subjects may expect some cooperation in the public good game and voting to exclude members can never be part of a sub-game perfect equilibrium strategy. Given the large body of experimental evidence supporting costly punishments, we decided to focus on equilibria in the repayment game for a given pattern of behavior in the other two stages. We think this is more appropriate in our setting where norms of exclusion for certain types of behavior persist in groups because they are beneficial on average rather than in each situation the group finds itself in. We therefore take the pattern of contributions to the public good as given and simply examine the conditions under which repayment by both types is rational.

With positive public good contributions, the gains from Stage 3 vary by type and our model generates the following predictions:

\footnotetext{
${ }^{7}$ Exclusion occurs when members get more than one vote against them, so a single member cannot exclude anyone.

${ }^{8}$ This discussion assumes that the repayment decision is determined by incentives rather than constrained by liquidity. This simplifies our exposition and allows us to emphasize the role of repayment incentives which are our main interest here. It is possible, that required repayment and expected returns from the public good game are both greater than the project return $\rho$. In such cases, repayment is constrained by liquidity. This was never the case in any round of our experiment.

${ }^{9}$ See, for example Andreoni (1995); Fehr and Gachter (2000); Andreoni and Vesterlund (2008); Nikiforakis (2008); Fischbacher and Gachter (2010).
} 
1. Given project characteristics, individual repayment rates are increasing in the number of successes within the group and decreasing in loan size.

2. Type $b$ members are more likely to default on their loans.

These predictions follow from the incentive compatibility condition in equation (2). Members default when required payments are larger than expected gains from the public good. For small enough loans, this condition will hold even when there are few successes in the group. As loan sizes increase, the wedge between the expected returns for the two types of members may result in $a$-Types contributing to repayment while $b$-Types default.

We now describe the experiment designed to test these predictions.

\section{Experimental design}

The experiment consists of 3 activities which correspond to the three stages of the game described in Section 2. Each session simulates a microfinance group with 10 members, five each of type $a$ and $b$. All subjects are assigned identification numbers. A subject's type and identifcation number is private information throughout a session.

To explore the effects of loan size on repayment rates, we use three treatments: Low, Medium and High. The per member loan required for investment is 20,50 and 80 Rupees respectively in the three treatments. We multiply this by 1.2 to account for interest in computing repayment amounts. Groups therefore have to reimburse either 240, 600 or 960 Rupees. These are the values taken by $n R_{l}$ across the three treatments. We conducted 6 sessions of the Low treatment and 7 each of the Medium and High treatments.

Each round begins with all subjects receiving a loan that is invested in a risky project. This is Activity 1. We set the project success probability $\pi=0.75$ and the return on a successful project to be $\rho=300$. The project outcome is private information to each group member to begin with and the total number of successes in the group is announced before each successful member decides whether or not to contribute towards repayment and privately informs the experimenter of this decision. Once all group members have informed the experimenter of their decision, the experiment announces the list of successful projects and the repayment decision of each successful member in the group are announced by ID number and recorded on a blackboard. ${ }^{10}$ Failed projects

\footnotetext{
${ }^{10}$ All decisions were recorded by subjects on strips of paper which were then folded and slipped into an envelope.
} 
generate no returns and these members cannot therefore contribute towards repayment. If there are enough contributors for the loan to be repaid, all contributors receive their project return of 300 minus their required repayment amount. This is simply the amount owed to the lender, which varies by treatment, divided by the number of contributors. Members with successful projects who decide not to contribute keep the entire project return. If a group defaults on the loan, all successful members keep the entire return of 300, the group does not undertake any additional activity in this round and a new round begins.

Groups that reimburse their loan move on to Activity 2. Each contributor can now cast a vote against any other member of the group. Members receiving two or more votes against them are expelled from the group for that round. Individual voting decisions are recorded but not revealed, only the identity numbers of the excluded members are announced. ${ }^{11}$

Those not excluded then move on to Activity 3, which is a variant of a public good game. Each member is now given an endowment of 100 Rupees and allocates it across a private and a group account. Benefits from the public account vary by type and are given by equation (1), with $\alpha_{a}=0.9$ and $\alpha_{b}=0.3$. The $a$-Types therefore gain 3 times more than the $b$-Types for a given level of $q$ and $C$. After contributions have been made, incomes for the two types from the public good are computed and announced and a new round begins. Total income from Activity 3 is the sum of the allocation to the private account and the gains from the public good.

We conducted 8 rounds in each of our 20 non-computerized sessions, with 10 subjects in each session, and so we have a total of 1600 observations. The experiment was conducted at the Delhi School of Economics in Delhi University and our subjects included both graduate and undergraduate students from several fields of study. The composition of the group remained unchanged during each session and each subject participated in exactly one session so we have 200 subjects. Types were assigned at the start of the session and stayed unchanged for all rounds. Each session lasted about 2 hours including reading of the instructions, a practice round and payment of money. The average subject payment was around 600 Rupees (equivalent to approximately 15 US dollars at the prevailing exchange rate). This payment was computed by adding the earnings from Activities 1 and 3 over the eight rounds of the experiment. The instructions for the High treatment and a schematic structure of the experiment (Figure 2) are in the Appendix.

\footnotetext{
${ }^{11}$ A member who abstains from voting leaves empty the slip of paper on which the vote is recorded. Since the contents of the slip are not observed by the other members, the total number of votes and their pattern is known only to the experimenter.
} 


\section{Results}

\section{Repayment behavior}

Table 1 reports the frequency distribution of successes and group default rates by treatment. The empirical distribution of successes in the experiment closely follows the theoretical binomial distribution. For our parameter values for example, the theoretical probability of either 7 or 8 successes is 0.53 , and the observed frequency of this event in our data is 0.55 . Since the project return was 300, repayment required at least one successful project under the Low treatment, 2 successful projects under the Medium treatment and 4 under the High treatment. The minimum number of successful projects in any session was 4 and repayment was therefore always feasible if enough members decided to contribute. The observed differences in behavior cannot therefore be attributed to liquidity constraints.

Table 1: Project Success Frequencies and Group Default by Treatment (\%)

\begin{tabular}{lcccccc}
\hline & \multicolumn{5}{c}{ Treatment } & \multicolumn{4}{c}{ Group Default } \\
Successes & Low & Medium & High & Total & Low and Medium & High \\
& & & & & & \\
\hline & & & & & & \\
4 & 0.0 & 1.8 & 1.8 & 1.2 & 0 & 100 \\
5 & 4.2 & 5.4 & 3.6 & 4.4 & 0 & 100 \\
6 & 10.4 & 12.5 & 3.6 & 8.8 & 0 & 100 \\
7 & 25.0 & 26.8 & 25.0 & 25.6 & 0 & 64.3 \\
8 & 18.8 & 30.4 & 37.5 & 29.4 & 0 & 28.6 \\
9 & 20.8 & 17.9 & 21.4 & 20.0 & 0 & 25.0 \\
10 & 20.8 & 5.4 & 7.1 & 10.6 & 0 & 25.0 \\
& & & & & & \\
\hline
\end{tabular}

We see sizable group default in the High treatment and none at all in the Medium and Low treatments. Groups under the High treatment were restricted to Activity 1 in $43 \%$ of their rounds because not enough members were willing to contribute to loan repayment. As expected, the rate of default was decreasing in the number of successes. Groups always defaulted on the loan if there were fewer than 7 successful projects in a round. Since group default results from individual repayment decisions we now turn to analyzing these to see if they are in line with the predictions discussed in Section 3 .

Individuals compare repayment amounts with the expected costs of exclusion as indicated in the incentive compatibility condition in (2). Repayment burdens vary due to differences in loan sizes 
and project success rates as shown in Table 2. A member in a High treatment group with 4 contributing successes must pay ten times what is required in a Low treatment group with 10 successes. These numbers and the corresponding differences between treatments would be even larger if some successful members were to default.

Table 2: Minimum contributions required for repayment

\begin{tabular}{lccc}
\hline & \multicolumn{3}{c}{ Treatment } \\
Successes & Low & Medium & High \\
& & & \\
\hline & & & \\
4 & 60 & 150 & 240 \\
5 & 48 & 120 & 192 \\
6 & 40 & 100 & 160 \\
7 & 34 & 86 & 137 \\
8 & 30 & 75 & 120 \\
9 & 27 & 67 & 107 \\
10 & 24 & 60 & 96 \\
& & & \\
\hline
\end{tabular}

The cost of exclusion from Activity 3 is the expected income from that activity which in turn depends on the borrower's type and the patten of contributions to the public good game. We consider three alternative set of strategies. The first two provide upper and lower bounds on such income while the third is based on outcomes observed in the experiment. In all cases, we focus on symmetric contributions by all members, conditional on their type. Since positive contributions to a public good is not part of an equilibrium strategy, but are often observed in experiments of this type, our approach is simply to take as given a pattern of contributions to the group account in Activity 3 and ask what contribution strategies in Activity 1 constitute an equilibrium.

Suppose first that all members follow a strategy of zero contributions to the group account in Activity 3 and members who vote in Activity 2 always vote against those who default in Activity 1. A member who expects all others to contribute towards loan repayment in Activity 1, would expect to be excluded if he defaults on the loan. In this case, the minimum cost of exclusion is equal to the endowment of 100 allotted to him at the start of Activity 3. We see from Table 2 that this is always greater than the minimum required payments for the Low loan treatment, it is mostly above these minimum requirements in the Medium treatment and always below the required repayment for the High treatment except when all group projects succeed. This example is a useful benchmark, both because it the unique Nash equilibrium of the public good game, and because it illustrates that even when we keep gains from the public good game at their minimum level, groups with small and medium loans are unlikely to default in contrast to those with high loans. ${ }^{12}$

\footnotetext{
${ }^{12}$ Under the Medium treatment, default should be observed if there are fewer than 6 successes, which happens in
} 
When public good contributions are positive, the gains from Activity 3 vary within a round. Type $a$ members earn more and therefore have better incentives to repay their loan in Activity 1 . To illustrate, suppose that all players allocate their entire endowment to the group account in Activity 3. Though this is an unlikely expectation, it provides us with an upper bound on the gains from Activity 3. The gains are 540 Rupees for Type $a$ and 180 Rupees for Type $b{ }^{13}$ As seen from Table 2 , a Type $a$ member would never default unilaterally in this case while a Type $b$ member would unilaterally default when there are fewer than 6 successful projects in the High treatment, even if this means exclusion with certainty. For the other two treatments, default by Type $b$ would occur if the number of successes falls below 2 for the Low treatment and 4 for the Medium treatment. We therefore expect the greatest asymmetry in the behavior of the two types under the High treatment.

Finally, suppose that expectations of income from Activity 3 are in fact close to the averages observed in our data. These are 200 Rupees for Type $a$ and 125 Rupees for Type $b$. Based on Table 2, we should observe no unilateral default by either type in the Low treatment since the required repayment is at most 60 Rupees. In the Medium treatment, Type $a$ would never default whereas Type $b$ would default when fewer than 5 projects are successful. Under the High treatment, default is much more likely, with $a$-Types defaulting when there are fewer than 5 successes and $b$ Types defaulting when there are fewer than 8 successes. For example, if there are 7 successful projects within the group, 6 belonging to Type $a$ and 1 to Type $b$, the Type $b$ member would default, irrespective of the behavior of the Type $a$, since the minimum contribution of 137 Rupees is greater than their expected gain. Those of Type $a$ contribute since their contribution of 160 Rupees is less than their expected gain of 200. In general, repayment rates under this treatment would fluctuate depending on the number of successful projects and their distribution across the two types of members. ${ }^{14}$

To summarize, all 3 scenarios considered so far predict that members in Low treatment groups will not default, those under the Medium treatment default if too few projects are successful and those under the High treatment default frequently. There is no difference between the two types for small enough loans because repayment burdens for these loans are small and the constraint given by equation (2) will not bind for either type. For groups in the High treatment, the repayment burden is sizable and, even when groups do reimburse their loan, we expect some individual default, especially among $b$-Types.

$7 \%$ of the rounds. Under the High treatment we would observe it in rounds with fewer than 10 successful projects or $93 \%$ of the rounds in the experiment.

${ }^{13}$ For Type $a$, the gains are $0.9 \times \frac{(0.9 \times 5)+(0.3 \times 5)}{10} \times 1000=540$ and for Type $b$, they are $0.3 \times \frac{(0.9 \times 5)+(0.3 \times 5)}{10} \times 1000=$ 180.

${ }^{14}$ In the above example, we intentionally chose only a single $b$-Type among the successful projects to ensure that this member would be excluded if all $a$-Types followed the strategy of voting against defaulters. The larger the number of defaulters, the lower the probability that any one of them is excluded. This complicates the calculation of expected costs and benefits. 
These predictions are broadly consistent with our data as can be seen from Table 3 . Under both Low and Medium treatments, contribution rates are above $90 \%$ in any round with 7 or more successful projects. Differences in the decision to contribute by type are not statistically significant in the Low treatment. Under the Medium treatment this difference across types is not very large though it is statistically significant at the $5 \%$ level for the pooled sample. In contrast, under the High treatment, $b$-Type members contribute only about half as often as the $a$-Types.

Table 3: Individual repayment by type, treatment and success rates (\%)

\begin{tabular}{|c|c|c|c|c|c|c|}
\hline \multirow{3}{*}{ Successes } & \multicolumn{6}{|c|}{ Treatment } \\
\hline & \multicolumn{2}{|c|}{ Low } & \multicolumn{2}{|c|}{ Medium } & \multicolumn{2}{|c|}{ High } \\
\hline & Type $a$ & Type $b$ & Type $a$ & Type $b$ & Type $a$ & Type $b$ \\
\hline 4 & - & - & 100 & 100 & 66.7 & 0 \\
\hline 5 & 100 & 100 & 100 & 44.4 & 83.3 & 25.0 \\
\hline 6 & 71.4 & 93.8 & 85.0 & 72.7 & 33.3 & 33.3 \\
\hline 7 & 100 & 95.3 & 94.4 & 90.2 & 66.7 & 28.3 \\
\hline 8 & 97.3 & 94.3 & 98.5 & 94.2 & 79.5 & 38.8 \\
\hline 9 & 97.7 & 97.8 & 93.5 & 91.0 & 71.7 & 49.1 \\
\hline 10 & 98.0 & 100 & 93.3 & 100 & 75.0 & 50.0 \\
\hline Average & $\begin{array}{c}96.3 \\
(1.23)\end{array}$ & $\begin{array}{c}96.9 \\
(1.37)\end{array}$ & $\begin{array}{c}94.8 \\
(2.18)\end{array}$ & $\begin{array}{c}88.7 \\
(1.54)\end{array}$ & $\begin{array}{c}73.7 \\
(3.25)\end{array}$ & $\begin{array}{c}39.2 \\
(3.02)\end{array}$ \\
\hline Difference $(p-$ value $)$ & 0.7 & & 0.0 & & 0.00 & $* * *$ \\
\hline
\end{tabular}

Standard errors in parenthesis. Differences across types are tested using a t-test. In this and all subsequent tables, ${ }^{*},{ }^{* *}$ and ${ }^{* * *}$ indicate statistical significance at the 10,5 and 1 per cent levels respectively.

Figure 1 illustrates the changing pattern of repayment rates by treatment and round. Repayment rates are falling by round for the High treatment, but not for the other two. The steadiest decline is for $b$-Type members under this treatment.

Table 4 estimates the determinants of the decision to contribute in a multivariate regression framework. Our theoretical model predicts default when the repayment liability exceeds expected benefits, thus violating the incentive compatibility condition in (2). Default rates are therefore discontinuous in the required repayment. The models we estimate are all continuous approximations of this default probability and the estimated coefficients cannot therefore be interpreted literally. It is however reassuring that they are of the right sign with higher default in rounds with smaller net benefits. The dependent variable is 1 if the group member chooses to contribute towards re- 
Figure 1: Loan repayment rates by round and treatment

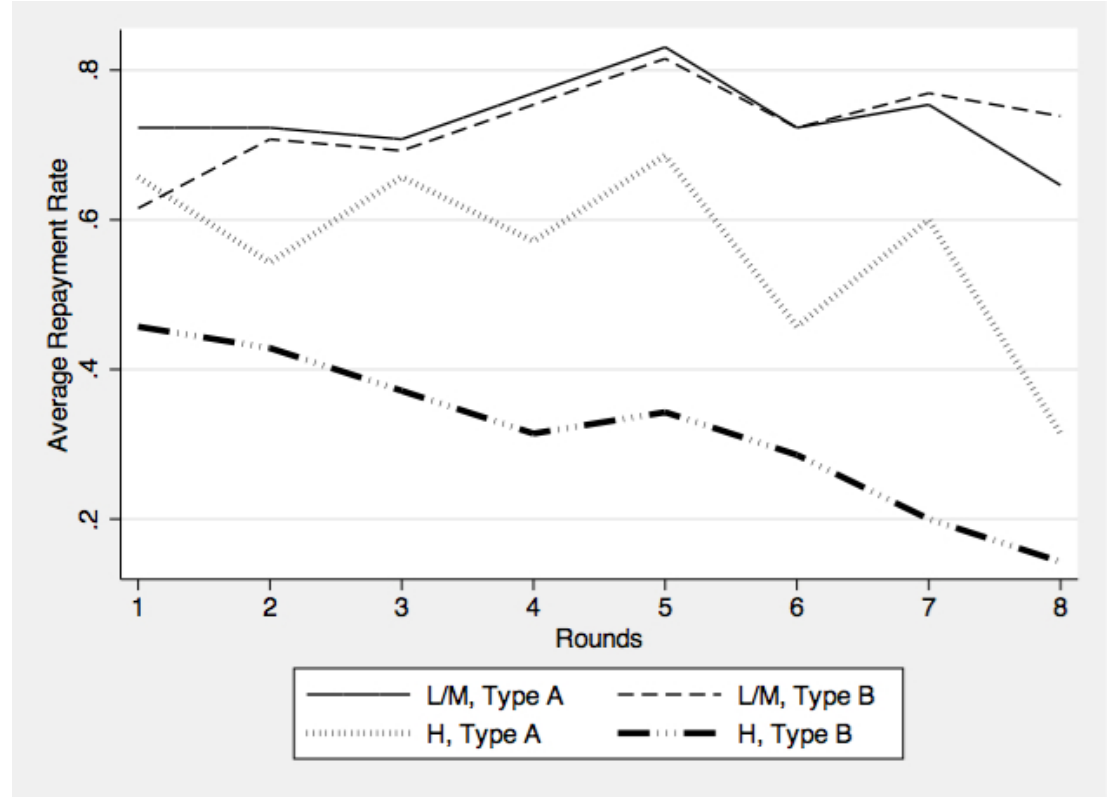

payment and 0 otherwise. The 1,248 observations correspond to all the successful projects in the experiment. Models (1) - (3) use a Probit specification while Model (4) uses a linear specification with member fixed-effects. To facilitate comparison across the models, we report marginal effects. As we have three treatments and two types, there are a total of six categories of borrowers. Model (1) estimates the propensity to contribute for each of these categories with the omitted category being $b$-Type members in the Low treatment. Models (2) - (4) test equation (2) more directly by including the required repayment and the costs of exclusion. Model (2) does this by using the repayment amount from Table 2 and the type of the borrower. Model (3) replaces borrower type by the average benefit from the public good game for each type of member. Model (4) includes member fixed-effects and thereby exploits the variation in required repayments for each individual within a session. This variation arises from the differences in project success rates across rounds. For example, when a group under the High treatment moves from 6 to 9 successful projects, the minimum required repayment decreases by 50 Rupees and Model (4) estimates that this change leads to a 12 percentage point decline in default.

In summary, the experimental data support both our predictions. Loan repayment rates are decreasing in loan size, increasing in project success rates and $b$-type members are more likely to default on large loans. We now turn to a description of behavior in the other two stages of our game. In the voting game, we are interested in the rate at which defaulters are punished, since these punishments are critical in turning potential sanctions into actual ones. For the public good game, we examine the patterns of contributions by type and loan size. 
Table 4: Choosing to Contribute towards Loan Repayment

\begin{tabular}{|c|c|c|c|c|}
\hline & Model 1 & Model 2 & Model 3 & Model 4 \\
\hline Type $a$ & $\begin{array}{l}-0.019 \\
(0.048)\end{array}$ & $\begin{array}{c}0.135^{* * * *} \\
(0.026)\end{array}$ & & \\
\hline Medium Loan Treatment & $\begin{array}{c}-0.234^{* * *} \\
(0.074)\end{array}$ & & & \\
\hline High Loan Treatment & $\begin{array}{c}-0.573^{* * *} \\
(0.060)\end{array}$ & & & \\
\hline Medium Loan $\times$ Type $a$ & $\begin{array}{c}0.090^{* *} \\
(0.041)\end{array}$ & & & \\
\hline High Loan $\times$ Type $a$ & $\begin{array}{c}0.142^{* * *} \\
(0.028)\end{array}$ & & & \\
\hline Required Repayment & & $\begin{array}{c}-0.339 * * * \\
(0.037)\end{array}$ & $\begin{array}{c}-0.399 * * * \\
(0.053)\end{array}$ & $\begin{array}{c}-0.240^{* * * *} \\
(0.060)\end{array}$ \\
\hline Expected Benefit & & & $\begin{array}{c}0.006^{* *} \\
(0.002)\end{array}$ & \\
\hline Constant & & & & $\begin{array}{c}1.043^{* * *} \\
(0.056)\end{array}$ \\
\hline Sample Size & 1,248 & 1,248 & 1,248 & 1,248 \\
\hline
\end{tabular}

\section{Exclusion}

All those contributing to loan repayment are eligible to vote. The top panel in Table 5 desrcibes voting behavior and the bottom panel reports the corresponding exclusion rates. Any member receiving two negative votes is excluded from participating in the subsequent public good game. About three-quarters of defaulters receive at least one vote against them, and over half of them are excluded. While those with failed projects are also sometimes excluded, these rates are significantly lower (see Table 5). Those contributing receive a negligible fraction of votes. These patterns are similar across all treatments.

The pattern of contributions to the public good determines the cost of exclusion in Stage 2 of the game. If those who default on their loans made zero contributions to the public good, a member would want to exclude a defaulter of type $b$ but not of type $a$. This can be computed from equation (1) using the values we assign to these parameters in the experiment. However those who default on the loan but are not excluded in Activity 2 on average contribute 18 Rupees to the group account. At this level of contribution, it is costly to exclude both types but we still observe that three-quarters of all defaulters receive a negative vote. These results on voting and exclusion are consistent with the large experimental literature which finds systematic evidence on the use of 
Table 5: Exclusion Rates

\begin{tabular}{|c|c|c|c|c|c|}
\hline & $\begin{array}{l}(1) \\
\text { All }\end{array}$ & $\begin{array}{c}(2) \\
\text { Contributors }\end{array}$ & $\begin{array}{c}(3) \\
\text { Defaulters }\end{array}$ & $\begin{array}{c}(4) \\
\text { Failures }\end{array}$ & $\begin{array}{c}(5) \\
\text { Difference }(p-\text { value })^{\dagger} \\
(3-4)\end{array}$ \\
\hline \multicolumn{6}{|c|}{ Panel A: Received at least One Vote } \\
\hline All & $\begin{array}{c}0.166 \\
(0.010)\end{array}$ & $\begin{array}{c}0.070 \\
(0.008)\end{array}$ & $\begin{array}{c}0.744 \\
(0.039)\end{array}$ & $\begin{array}{c}0.234 \\
(0.025)\end{array}$ & $0.000^{* * *}$ \\
\hline Low and Medium & $\begin{array}{c}0.158 \\
(0.011)\end{array}$ & $\begin{array}{c}0.082 \\
(0.010)\end{array}$ & $\begin{array}{c}0.833 \\
(0.054)\end{array}$ & $\begin{array}{c}0.267 \\
(0.029)\end{array}$ & $0.000^{* * *}$ \\
\hline High & $\begin{array}{l}0.194 \\
(0.022)\end{array}$ & $\begin{array}{c}0.021 \\
(0.010)\end{array}$ & $\begin{array}{l}0.688 \\
(0.053)\end{array}$ & $\begin{array}{c}0.093 \\
(0.040)\end{array}$ & $0.000^{* * *}$ \\
\hline \multicolumn{6}{|l|}{ Panel B: Excluded } \\
\hline All & $\begin{array}{c}0.075 \\
(0.007)\end{array}$ & $\begin{array}{c}0.011 \\
(0.008)\end{array}$ & $\begin{array}{c}0.52 \\
(0.045)\end{array}$ & $\begin{array}{c}0.094 \\
(0.017)\end{array}$ & $0.000^{* * *}$ \\
\hline Low and Medium & $\begin{array}{c}0.063 \\
(0.008)\end{array}$ & $\begin{array}{c}0.013 \\
(0.004)\end{array}$ & $\begin{array}{c}0.604 \\
(0.071)\end{array}$ & $\begin{array}{c}0.112 \\
(0.021)\end{array}$ & $0.000^{* * *}$ \\
\hline High & $\begin{array}{c}0.116 \\
(0.018)\end{array}$ & $\begin{array}{c}0.000 \\
(-)\end{array}$ & $\begin{array}{c}0.467 \\
(0.057)\end{array}$ & $\begin{array}{c}0.019 \\
(0.019)\end{array}$ & $0.000^{* * *}$ \\
\hline
\end{tabular}

Standard errors in parenthesis. Statistical significance is based on a t-test for differences in means.

costly punishments as an enforcement device.

We also examine if the decision to sanction varies by type and treatment and find that the fraction of eligible voters who actually vote against loan defaulters is largest under the High treatment with over $80 \%$ of eligible voters actually voting. This is about twice the fraction in the other treatments. Given the quality of the group, sanctioning is always more costly for Type $a$ since, by assumption, they gain more from contributions to the public good. We might therefore expect that they sanction less frequently than the $b$-Types. We test the null hypothesis of equal fractions of voters of both types against the alternative of unequal fractions. We cannot reject the null for the High treatment, but do reject it in the Low and Medium treatments (see Table 6). One possible explanation for the greater use of sanctions by both types under the High treatment is that enforcement is more critical in ensuring the repayment of the group loan than in the other two cases and one or two defaulters can more easily trigger group default. 
Table 6: Voting behavior by type and treatment

\begin{tabular}{lccc}
\hline & Type $a$ & Type $b$ & $\begin{array}{c}\text { Difference } \\
\text { (p-value) }\end{array}$ \\
& & & \\
\hline & & & \\
Low and Medium Loan & 0.36 & 0.47 & $0.003^{* * *}$ \\
& $(0.025)$ & $(0.026)$ & \\
High Loan & 0.87 & 0.80 & 0.175 \\
& $(0.031)$ & $(0.048)$ & \\
\hline
\end{tabular}

Standard errors in parenthesis. Statistical significance is based on a t-test for differences in means.

\section{The public good game}

The average contribution to the group account is 26 Rupees ( $26 \%$ of the endowment of 100 Rupees). We also find partial evidence in support of Nash behavior as $28 \%$ of the contributions to the group account are equal to zero. We however never observe the Nash equilibrium of zero contributions by all members in a single round. We also find differences by treatment with members of both types under the High treatment contributing 20 to $40 \%$ more than their counterparts in other treatments. Under the Low and Medium treatments, 35\% of the contributions are equal to zero while this is true only of $14 \%$ of the contributions under the High treatment.

The allocation to the public good varies across types, with Type $a$ players contributing on average $76 \%$ more than Type $b$ players. We perform a Mann-Whitney Wilcoxon rank sum test for first-order stochastic dominance of the distribution of contributions by Type $a$ relative to Type $b$ and reject the equality of these distributions for all treatments (see Table 7). While both types of players would gain from keeping the marginal rupee in their private rather than group account, the return from the group account is higher for $a$-Types and this may explain their higher contributions. These higher contributions could also reflect concerns for fairness, since they earn a disproportionate share of total earnings from this stage of the game.

\section{Conclusion}

Microfinance groups often engage in activities that are not directly related to credit, yet little is known about how these ancillary activities influence group repayment behavior. In this paper, we report results from a laboratory experiment explicitly designed to highlight their importance in encouraging compliance in credit contracts. Groups in our experiment first make repayment 
Table 7: Average contributions to the public good

\begin{tabular}{lcccc}
\hline & All & Type $a$ & Type $b$ & $\begin{array}{c}F_{b}>F_{a} \\
(\mathrm{p} \text {-value }\end{array}$ \\
& & & & \\
\hline \multirow{3}{*}{ All } & & & & \\
\multirow{2}{*}{ Low and Medium Loan } & 25.92 & 32.85 & 18.70 & $0.000^{* * *}$ \\
\multirow{3}{*}{ High Loan } & $(0.91)$ & $(1.39)$ & $(1.09)$ & \\
& $(1.00)$ & $(1.59)$ & $(1.14)$ & $0.000^{* * *}$ \\
& 31.47 & 37.52 & 24.35 & $0.000^{* * *}$ \\
& $(2.07)$ & $(2.90)$ & $(2.85)$ & \\
\hline
\end{tabular}

Standard errors in parenthesis. Reported p-values are from a rank sum test of first order stochastic dominance of the distribution of the $a$-types.

decisions under joint liability contracts and then undertake a variant of a standard public good game. To identify the role played by repayment incentives, we exogenously vary loan sizes across groups and introduce heterogeneity in the returns from the public good across group members. Members contributing to loan repayment have the option of excluding those who do not and such sanctions can potentially be used as an enforcement device. If members decide to default based on a comparison of the expected costs of exclusion with those of loan repayment, we expect the highest default rates among those with large loans and low returns from the public good.

In line with our theoretical predictions, we find that repayment decisions are guided by selfinterested motives. Groups with large loans are most likely to default. We also find that differences in repayment burdens resulting from exogenous variation in the number of successful projects influence default rates. Within groups, those with the smallest gains from the public good contribute less often to loan repayment. We do however also find evidence of pro-social behavior in the other stages of the experiment. Members make voluntary contributions to the public good, which goes against their profit maximizing incentives. They also actively sanction defaulters by excluding them, even though this is costly as it lowers their expected return from the public good.

These results suggest that the collective activities undertaken by microfinance groups are not incidental and can be directly linked to their performance. From a policy perspective, one could argue that the development of alternative activities by microfinance groups should be encouraged as a way to increase their ability to sanction defecting members. In doing so however, it is critical that the returns from such activities be sizable and evenly distributed across members. This is particularly true of the ultra-poor households who operate in precarious environments and may be more susceptible to default. 


\section{A.1 Appendix}

Figure 2: Structure of the Experiment

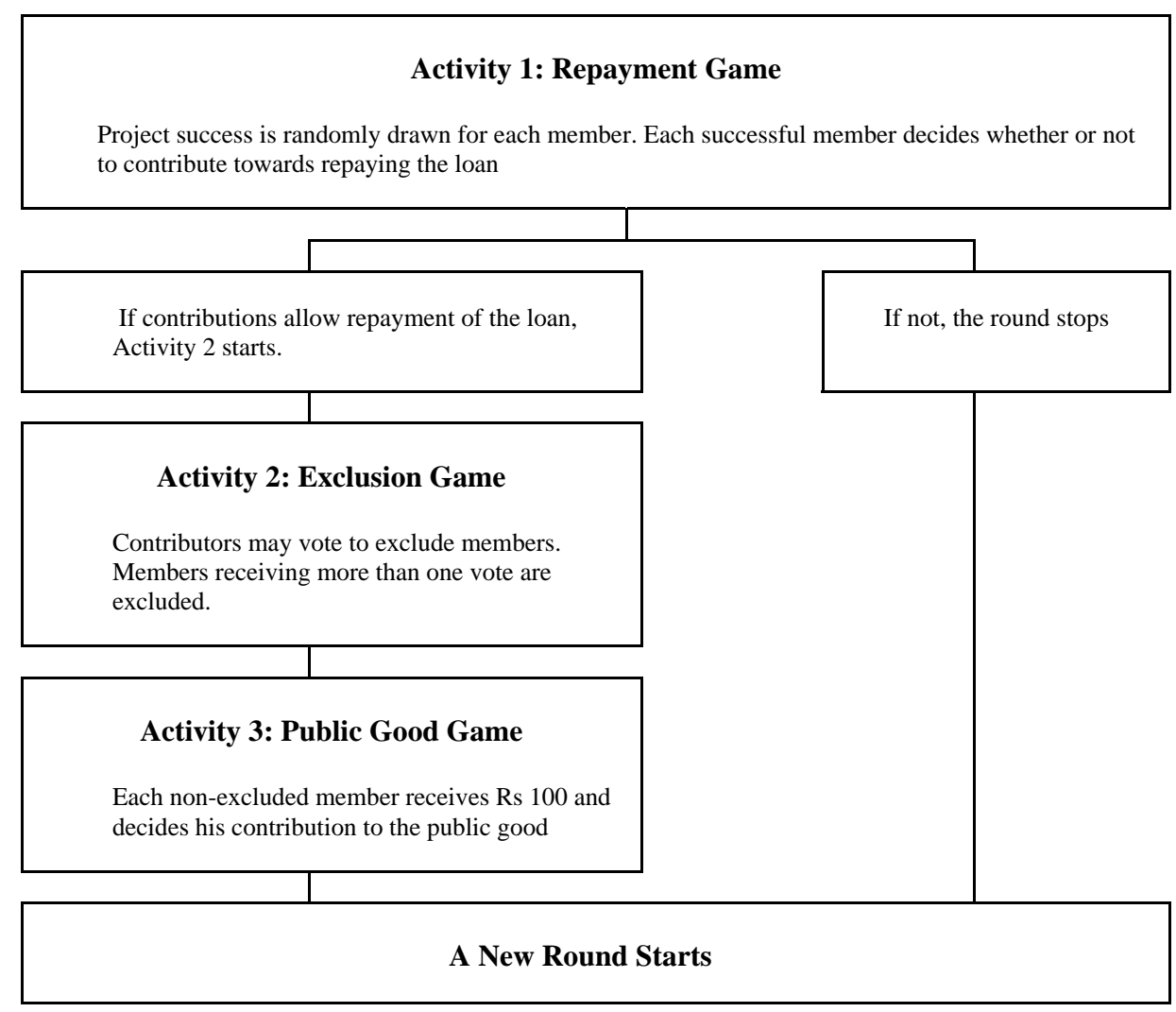




\section{Instructions:}

ID:

Type:

This is an experiment in the economics of decision-making. The instructions are simple and if you follow them carefully and make good decisions you will earn money that will be paid to you privately in cash at the end of the experimental session. Your earnings will be in experimental rupees (ERs), which will be converted into real rupees (Rs) at the following exchange rate: Experimental rupees $=$ Rs 1 .

In today's experiment you will take part in 3 different activities (we will call them Activity 1, Activity 2 and Activity 3). Your ID number and your type are provided on the top left hand corner of this page. You can be type A or type B. Each type has a number associated with it: $\mathrm{A}=0.9$ and $\mathrm{B}=0.3$. This number will determine your income in Activity 3 . There are equal number of types in each group (i.e., there are 5 type A's and 5 type B's). Attached to the instructions you will also find a record sheet. Please do not reveal your type or show your record sheet to any other member of your group.

You will participate in Activity 110 times. The number of times you continue on to Activity 2 and Activity 3 will depend on the outcome of Activity 1 in a manner to be explained below.

\section{Activity 1:}

For this activity you are in a group of ten individuals each of whom has received a business improvement loan. Each member of your group has received a loan of ERs 80 to operate a business. If your business is successful you will earn ERs 300, if your business is not successful you will earn nothing. There are 10 members in your group, the group as a whole must pay back ERs 960 (in that case we will say that the debt has been repaid). If the debt is fully repaid, we will continue on to Activity 2 and Activity 3 . If not we stop and go to the next round.

\section{Earnings}

In this activity you have to draw a ball from the bag in front of you, to determine if your business is successful or not (i.e., whether you earn money or not). There are a total of three green balls and one red ball in the bag.

- If you draw a green ball your business is successful and you earn ERs 300.

- If you draw a red ball your business fails and you earn zero.

This means that each of you has a one in four chance of earning zero. It is possible that more than one of you will draw a red ball. It is also possible that none of you will draw a red ball. Depending on the colour of the ball drawn, please circle R (red) or G (green) in column 2 of the attached record sheet. After you have drawn the ball and noted the colour (and written it in column 2), please return the ball to the bag. The colour of the ball chosen will be recorded by the experimenter. Once all 10 individuals have drawn a ball, the total number of members who have drawn a green ball will be announced. Write this in column (3) of your record sheet.

Loan Repayment 
If you have drawn a green ball you must decide whether you want to contribute towards group repayment. If you choose to contribute, please circle Y in column (4) of the attached record sheet; if you choose not to contribute, please circle $\mathrm{N}$ in the same column. Also record this decision on the strip of paper provided for this round and this Activity (look at the experimenter to see a sample). The experimenter will collect this from you. If a person draws a red ball from the bag she has earned zero and therefore cannot repay in this round.

The actual amount you will be asked to contribute will depend on the number of group members who draw a green ball and choose to contribute. Since the total amount that needs to be repaid is ERs 960, the more people in the group who contribute to loan repayment, the less each person will have to pay.

Your income from Activity 1 will be calculated in the following way:

\begin{tabular}{|l|l|l|l|l|l|l|}
\hline $\begin{array}{l}\text { Number of } \\
\text { group } \\
\text { members } \\
\text { choosing to } \\
\text { contribute }\end{array}$ & $\begin{array}{l}\text { Contribution } \\
\text { amount of } \\
\text { each } \\
\text { member } \\
\text { choosing to } \\
\text { contribute }\end{array}$ & $\begin{array}{l}\text { Income of } \\
\text { each } \\
\text { member } \\
\text { choosing to } \\
\text { contribute }\end{array}$ & $\begin{array}{l}\text { Income of } \\
\text { each } \\
\text { member } \\
\text { choosing } \\
\text { not tot } \\
\text { contribute }\end{array}$ & $\begin{array}{l}\text { Income of } \\
\text { each } \\
\text { member } \\
\text { unable to } \\
\text { contribute }\end{array}$ & $\begin{array}{l}\text { Loan } \\
\text { repaid? }\end{array}$ & $\begin{array}{l}\text { Go on to } \\
\text { activity } \\
\text { 2 and 3 }\end{array}$ \\
\hline 0 & 0 & 300 & 300 & 0 & No & No \\
\hline 1 & 0 & 300 & 300 & 0 & No & No \\
\hline 2 & 0 & 300 & 300 & 0 & No & No \\
\hline 3 & 0 & 300 & 300 & 0 & No & No \\
\hline 4 & 240 & 60 & 300 & 0 & Yes & Yes \\
\hline 5 & 192 & 108 & 300 & 0 & Yes & Yes \\
\hline 6 & 160 & 140 & 300 & 0 & Yes & Yes \\
\hline 7 & 137 & 163 & 300 & 0 & Yes & Yes \\
\hline 8 & 120 & 180 & 300 & 0 & Yes & Yes \\
\hline 9 & 107 & 193 & 300 & 0 & Yes & Yes \\
\hline 10 & 96 & 204 & NA & NA & Yes & Yes \\
\hline
\end{tabular}

Notice that for the group to move on to Activities 2 and 3, at least 4 group members should choose to contribute.

After every group member has made his/her decision, the experimenter will display on the whiteboard the contribution amount of each member who chose to contribute and whether this member drew a red ball or a green ball. Write down your contribution amount in column (5) of the record sheet if you drew a green ball. If you chose not to contribute your contribution amount is always 0. Calculate your income from activity 1 as ERs 300 minus your actual contribution amount (number in column (5)). Write this in column (6) of the attached record sheet. Remember if you drew a red ball, you cannot contribute and your income for this round is 0 .

At the end of each round the experimenter will announce whether the loan has been repaid or not and whether you move on, as a group, to Activity 2 and 3 or not.

If the loan is not repaid, then you forego the chance to earn income from Activity 3 (below). The round ends here and your income from this round is simply your income from Activity 1. 
Write this number in column (13) of the attached record sheet. We now go to round 2 where we start with Activity 1 all over again.

\section{Activity 2}

Suppose you are eligible to participate in Activity 2 and Activity 3. Each member of the group who drew a green ball and chose to make a positive contribution towards debt repayment will be allowed to vote out one person from participating in Activity 3. Please write down the ID number of the person you want to vote out in column (7) of your record sheet. Remember you can vote out any member of the group. You can of course choose not to vote out any member of your group. Also record this decision on the strip of paper provided for this round and this Activity. The experimenter will collect this from you.

We will add up the votes and any member of the group who receives more than one vote will be voted out and will not be eligible to participate in Activity 3. If no one receives a vote, no member is voted out. Also you need to receive more than one vote to be excluded from Activity 3. So the number of members of the group who go on to Activity 3 can vary (depending on the number of members voted out).

After everyone has made their decision we will announce the number and ID of individuals voted out. Write down the total number of individuals voted out in column (8) of the attached record sheet. Remember the total number remaining is 10 minus total number voted out.

\section{Activity 3}

Those group members, who have not been voted out, now participate in Activity 3. It does not matter if you drew a red or a green ball in Activity 1 or you chose to contribute in Activity 1. You can participate in Activity 3 as long as you have not been voted out in Activity 2.

For this activity you are given an endowment of ERs 100, which you can choose to keep with you in a private account or place in a group account. Each ERs kept in the private account gives you ERs 1 .

The return on the money you place in the group account will depend on

(1) your type;

(2) the number of individuals of each type (type A or type B) remaining.

The earnings from the group account will be calculated in the following manner.

Income from Activity 3:

If you are of type A:

$\left[\frac{(\text { Number of type A remaining } \times 0.9)+(\text { Number of type B remaining } \times 0.3)}{\text { Total number of members remaining }}\right] \times G \times 0.9$

If you are of type B:

$\left[\frac{(\text { Number of type A remaining } \times 0.9)+(\text { Number of type B remaining } \times 0.3)}{\text { Total number of members remaining }}\right] \times G \times 0.3$ 
$G$ is the total amount placed in the group account by all the members participating in Activity 3 .

Remember you know your type but you do not know the type of the others.

Please write down the amount you wish to keep with you in your private account in column (9) of the record sheet. The amount you then place in the group account is given by ERs 100 minus what you keep in the private account. Write this number in column (10) of the record sheet. Record the amount you want to place in the group account on the strip of paper provided for this round and this Activity. The experimenter will collect this from you.

Once all of you have decided on your contribution to the group account, we will calculate your income from the group account. We will write this on the whiteboard. Write this in column (11) of the record sheet. Your income from Activity 3 will then be the sum of the amount you kept in the private account (column (9)) plus your income from the group account (column (11)). Write this in column (12).

Let us consider an example. Suppose 9 members are eligible to participate in Activity 3. Of these 9 members, suppose 4 are of type A and 5 are of type B. The information on how many of each type are remaining will not be provided to you, this is just an example. Also suppose that the total contribution to the group account is ERs 400 (by all members of the group who participate in Activity 3). Then the income of a type A individual is $\left[\frac{(4 \times 0.9)+(5 \times 0.3)}{9}\right] \times 400 \times 0.9=$ ERs 204 and the income of a type B individual is $\left[\frac{(4 \times 0.9)+(5 \times 0.3)}{9}\right] \times 400 \times 0.3=$ ERs 68 . Your total income from activity 3 is then the sum of your income from the group account plus the amount you had placed in the private account.

Your total income from this round is the sum of your income in Activity 1 (column (6)) and Activity 3 (column (12)). Please write this in column (13) of the record sheet.

Please write your cumulative income (total income from all rounds in the experiment this far) in column (14) of the record sheet.

We then move on to Round 2, which works exactly in the same manner.

Are there any questions before we begin? 


\section{References}

Abbink, K., B. Irlenbusch, And E. Renner (2006): "Group Size and Social Ties in Microfinance Institutions," Economic Inquiry, 44(4), $614-628$.

Anderson, S., AND J.-M. BAland (2002): "The Economics of Roscas and intra-household resource allocation," Quarterly Journal of Economics, 117(3), 963-95.

Andreoni, J. (1995): "Cooperation in Public Goods Experiments: Kindness or Confusion?," American Economic Review, 85(4), 891-904.

Andreoni, J., W. T. H., AND L. Vesterlund (2008): Altruism in Experiments2nd edn.

AokI, M. (2001): Toward a comparative institutional analysis. MIT press.

Baland, J., R. Somanathan, And L. Vandewalle (2008): "Microfinance lifespans: A study of attrition and exclusion in self-help groups in India," in India Policy Forum, vol. 4, pp. 159-210.

Besley, T., AND S. CoAte (1995): "Group lending, repayment incentives and social collateral," Journal of Development Economics, 46(1), 1-18.

Cason, T. N., L. Gangadharan, And P. Maitra (2012): "Moral Hazard and Peer Monitoring in a Laboratory Microfinance Experiment," Journal of Economic Behavior and Organization, Forthcoming.

Cinyabuguma, M., T. Page, and L. Putterman (2005): "Cooperation under the threat of expulsion in a public goods experiment," Journal of Public Economics, 89, 1421-1435.

Fehr, E., AND S. Gachter (2000): "Cooperation and punishment in public goods experiments," The American Economic Review, 90, 980-994.

Fellner, G., Y. Lida, S. Kroger, AND E. SeKi (2010): "Heterogeneous productivity in voluntary public good provision: an experimental analysis," Working paper.

Fischbacher, U., AND S. Gachter (2010): "Social preferences, beliefs, and the dynamics of free riding in public goods experiments," The American Economic Review, 100(1), 541-556.

Giné, X., P. Jakiela, D. Karlan, And J. Morduch (2010): "Microfinance games," American Economic Journal: Applied Economics, 2(3), 60-95.

GREIF, A. (1993): "Contract enforceability and economic institutions in early trade: The Maghribi traders' coalition," The American economic review, pp. 525-548.

NiKIFORAKIs, N. (2008): "Punishment and counter-punishment in public good games: Can we really govern ourselves?," Journal of Public Economics, 92(1-2), 91-112.

Ostrom, E., J. Walker, AND J. R. Gardner (1992): "Covenants with and without a sword: self governance is possible," American Political Science Review, 86, 404-417. 
Platteau, J. (2006): "Solidarity norms and institutions in village societies: Static and dynamic considerations," Handbook on the Economics of Giving, Reciprocity and Altruism, 1, 819-886.

Putnam, R. (1994): Making democracy work: Civic traditions in modern Italy. Princeton Univ Press.

RAI, A., AND S. RAVI (2011): "Do Spouses Make Claims? Empowerment and Microfinance in India," World Development, 39(6), $913-921$.

Reuben, E., And A. Riedl (2009): "Enforcement of Contribution Norms in Public Good Games with Heterogeneous Populations," Cesifo working paper.

Sebstad, J., AND M. Cohen (2001): "Microfinance, risk management, and poverty," Washington, DC: CGAP.

TAN, F. (2008): "Punishment in a linear public good game with productivity heterogeneity," De Economist, 156, 269-293. 